\title{
BMJ Open Drivers for successful long-term lifestyle change, the role of e-health: a qualitative interview study
}

\author{
Carl Joakim Brandt,, ${ }^{1,2}$ Jane Clemensen,, ${ }^{2,3}$ Jesper Bo Nielsen, ${ }^{1}$ Jens Søndergaard ${ }^{1}$
}

To cite: Brandt CJ,

Clemensen J, Nielsen JB, et al. Drivers for successful long-term lifestyle change, the role of e-health: a qualitative interview study. BMJ Open 2018;8:e017466. doi:10.1136/ bmjopen-2017-017466

- Prepublication history and additional material for this paper are available online. To view these files, please visit the journal online (http://dx.doi. org/10.1136/bmjopen-2017017466).

Received 28 August 2017 Revised 26 January 2018 Accepted 6 February 2018
Check for updates

${ }^{1}$ Research Unit of General Practice, Department for Public Health, University of Southern Denmark, Odense, Denmark ${ }^{2}$ CIMT - Centre for Innovative Medical Technology, University of Southern Denmark, Odense, Denamrk

${ }^{3}$ Hans Christian Andersen's Childrens Hospital, Odense University Hospital, Odense, Denmark

Correspondence to Dr Carl Joakim Brandt; cbrandt@health.sdu.dk

\section{ABSTRACT}

Objectives Assisting patients in lifestyle change using collaborative e-health tools can be an efficient treatment for non-communicable diseases like diabetes, cardiovascular disease and chronic obstructive lung disease that are caused or aggravated by unhealthy living in the form of unhealthy diet, physical inactivity or tobacco smoking. In a prospective pilot study, we tested an online collaborative e-health tool in general practice. The aim of this study was to identify drivers of importance for longterm personal lifestyle changes from a patient perspective when using a collaborative e-health tool, including the support of peers and healthcare professionals.

Setting General practice clinics in the Region of Southern Denmark.

Participants 10 overweight patients who had previously successfully used a hybrid online collaborative e-health tool with both face-to-face and online consultations to lose weight.

Results The main themes identified were facilitators, barriers and support from family and peers. Establishment of a trustworthy relationship with the healthcare professionals was of paramount importance. It was important for the patients to monitor the measurable outcomes with realistic goals and feedback from a trusted person. Often, significant life events were identified as catalysts for successful long-term lifestyle changes. Dominant barriers to change were perception of insurmountable obstacles, experience of lack of selfefficacy and excess eating of high-calorie food. Finally, experiencing of trustworthy person-to-person forums, need for acknowledgement from referent others and support from family and peers were important drivers for long-term lifestyle change.

Conclusion The most important driver in long-term weight loss was a strong relationship with a healthcare professional. Collaborative e-health tools can support the relationship and behavioural changes through monitoring and providing relevant feedback. The support from family and peers also matters, and long-term success depends on the ability to establish strong, positive support on a dayto-day basis.

\section{BACKGROUND}

Many non-communicable diseases such as diabetes, cardiovascular diseases, cancer and chronic obstructive lung disease (COPD) are caused or aggravated by common
Strengths and limitations of this study

This study identified drivers for successful longterm lifestyle change among patients having used a collaborative online e-health tool in general practice.

- This study mainly included patients with successful long-term lifestyle change; therefore, reasons for lack of engagement and non-adherence might have been overseen.

- Authors CJB and JS both are general practitioners, which might have influenced their prejudices; however, all authors took this into consideration when analysing the data.

preventable risk factors, for example, tobacco use, unhealthy diet and physical inactivity. Although being overweight and having an unhealthy lifestyle can be uncomfortable, changing lifestyle is extremely difficult. For weight loss to have a positive impact on health, it needs to be sustainable and especially longterm lifestyle changes (defined as more that 12-18 months) have proven difficult. ${ }^{1}$ One of the major challenges for lifestyle change seems to be that social relationships are often challenged by peers, who do not understand the importance of the lifestyle change to the person. ${ }^{2}$ This might be one of the reasons why patients find it difficult to acknowledge the complexities and ambivalences that are part of using collaborating e-health tools. ${ }^{3}$

Even though recent systematic reviews have concluded that internet and mobile interventions can improve lifestyle behaviours, most studies had no more than 3-6 months' follow-up, which emphasises the need for research in long-term interventions. ${ }^{4-6}$ Most e-health tools and electronic lifestyle monitors use behavioural change techniques such as self-monitoring, goal setting and social support. ${ }^{7}$ In systematic reviews, adding personal feedback seems to improve outcome in comparison to automated response feedback. ${ }^{8}$ 
Several key theories of change from the field of behavioural science are employed in many lifestyle change and e-health tools, and have been used in this study as well. In accordance with social cognitive theory (SCT), a number of constructs come into play when patients try to change lifestyle. SCT has five constructs: (1) measurable outcome, such as, steps, (2) proximal goal setting, such as, daily breakfast, (3) procedural knowledge instead of content knowledge, such as, to walk 10000 steps daily instead of 'live healthy', (4) perceived self-efficacy such as to experience to reach planned goals and (5) social structural factors, such as, the influence of experiencing support (or obstruction) for a healthier lifestyle from family or peers. ${ }^{9}$ The social action theory (SAT) takes it one step further and explains how goal-directed action can lead to cognitive change that ultimately restructures the environmental context, including social relations, for long-term lifestyle change. ${ }^{10}$ Finally, the theory of triadic influence (TTI) outlines that to be successful, three streams of information need to be recognised: the intrapersonal stream, the interpersonal stream and the social environmental stream, indicating the complexity of helping a patient change from an unhealthy lifestyle to a healthy lifestyle. ${ }^{11}$

Therefore we anticipate that the outcome expectations and goal setting need to be developed in collaboration between a health coaching professional and the patient in order to have a longer-lasting effect for the patient. The internet and the rise of social media have changed our social patterns, and it has become possible to build relationships through digital tools. Some studies suggest that certain groups of patients might also benefit from this. $^{12}$

In a previous study, we found that a collaborative online e-health tool could support a significant weight loss of $7.0 \mathrm{~kg}$ during a 20 -month period in a general practice setting. The collaborative e-health tool was used in a hybrid manner, beginning with a personal meeting and included various behavioural change techniques such as joint goal setting, tailored information, self-monitoring, lifestyle coaching, in-person feedback, reminders and person-to-person support. ${ }^{13}$ A second version of the same collaborative e-health tool showed similar results for men with diabetes, who had an average $5.4 \mathrm{~kg}$ weight loss during a 12-month period (compared with $2.8 \mathrm{~kg}$ for a control group) in a municipal setting. Semistructured interviews with patients in the later study suggested that the initial face-to-face meeting was important for building a trustworthy relationship. ${ }^{14}$ But overall, the important drivers for such a lifestyle change and what role the collaborative e-health tool played has not previously been addressed.

Hence, we aimed to identify drivers of importance for weight loss management for patients, who had used a hybrid collaborative online e-health tool for weight loss, taking into account the patient's perspectives having experienced a collaborative e-health model.
METHODS

\section{Design}

To create new knowledge about the essential themes for this group of patients, we used qualitative, semistructured, individual interviews to explore the field without distraction.

\section{Context}

Ten overweight patients from a rural area in the Region of Southern Denmark were recruited for the study. They had all participated in the previous study that used a hybrid collaborative online e-health tool also involving face-to-face meetings.

\section{Sampling}

Purposive sampling was conducted among patients who had participated in the prior study with regard to gender, age and weight loss. Three men and seven women, ages 34-71, average age 52, with an average weight of $109 \mathrm{~kg}$ and a median weight loss of $10.5 \mathrm{~kg}$ (from 2 to $16 \mathrm{~kg}$ ) during the 20-month study period were invited. Six had been consistently interacting with the designated healthcare professional during the study, two stopped responding to information given, one left the study early and one never started. Invitations for this qualitative study were by phone and none declined the invitation.

\section{The intervention}

The collaborative online e-health tool was used as a supplemental tool for a dietician working in general practice, making sure that the relationship was established in-person before beginning the online communication. The same dietician met the patient in the clinic and handled the online lifestyle coaching with the patient. Apart from the dietician, the patients could meet and share health data/information with other patients in the online forums established through the collaborative e-health tool (online supplementary appendix 1). This developed into a strong community where it was also possible for patients to discuss many personal issues. ${ }^{13}$

\section{Interview procedure}

The interviews presented in this study took place 5 years after the end of the initial intervention. All patients were interviewed for $45 \mathrm{~min}$ to 1 hour and a relaxed atmosphere was achieved by holding the interviews one to one in the patients' homes, except for two who preferred to be interviewed in the medical centre. All interviews were carried out by $\mathrm{CJB}$, who has worked as a general practitioner (GP) for more than 10 years and with different e-health tools for more than 15 years, including the e-health tool used in the intervention. Before every interview, CJB briefly explained the purpose and nature of the research, answered questions, and provided participants with a description of the study in layman's terms. CJB explained to the patients that the interview data would be anonymised, and an informed consent document was signed by both the patient and CJB. The ethics committee for the Region of Southern Denmark reviewed the 


\section{Table 1 Interview guide}

\begin{tabular}{|c|c|}
\hline Fields of interest & Probing questions \\
\hline $\begin{array}{l}\text { Disease history } \\
\text { Experience with } \\
\text { taking action to } \\
\text { change lifestyle } \\
\text { Experience with } \\
\text { support from health } \\
\text { professionals and } \\
\text { peers }\end{array}$ & $\begin{array}{l}\text { Do you have any diseases? What } \\
\text { does that mean to you? What does } \\
\text { it mean for your well-being? How do } \\
\text { you see your health in general? } \\
\text { Have you ever taken the initiative to } \\
\text { improve or change your lifestyle? } \\
\text { How did it go? } \\
\text { Who has helped you with your health } \\
\text { challenges? Who has been the best } \\
\text { to help you? How? What was the } \\
\text { worst experience? How? }\end{array}$ \\
\hline $\begin{array}{l}\text { Experience with } \\
\text { and thoughts about } \\
\text { e-health tools }\end{array}$ & $\begin{array}{l}\text { Do you have a smartphone? Have } \\
\text { you ever used apps or the internet } \\
\text { in relation to your health or well- } \\
\text { being? Have you found recipes on } \\
\text { the internet? Have you used apps in } \\
\text { relation to exercise? }\end{array}$ \\
\hline
\end{tabular}

protocol and found that the Medical Research Involving Human Subjects Act does not apply to this study. ${ }^{15}$ A formal approval was therefore not required for this study. We did obtain written consent nevertheless, due to the sensitivity of the subject matter.

The semistructured interviews followed an interview guide, which resulted in an iterative approach, for emerging themes and perspectives to be explored. ${ }^{16}$ The semistructured interviews were segmented into four fields of interest: (1) patient disease history, (2) patient experiences with taking action to change lifestyle, (3) patient experiences with support from health professionals and peers and (4) patient experiences with and thoughts about e-health tools (see table 1).

The interview guide was tested among family and colleagues prior to use. All interviews were audiotaped. Field notes were made during and immediately after the interviews.

\section{Analysis}

All interviews were transcribed and uploaded to a common database verbatim. Transcripts were analysed by the researchers (CJB, JC, JBN and JS) using thematic analysis. An explorative approach was applied for systematic text condensation. ${ }^{17} 18$ The process began with reading the transcripts. After the initial four interviews, the authors conducted an overview of the transcripts and identified themes of importance. The authors then agreed on codes across ideas and themes that could be categorised. CJB then coded all transcripts in accordance with the agreed codes. The coded transcripts were shared and discussed. Data from each theme were condensed and summarised into concepts and generalised descriptions. Several times throughout the process, identified themes were compared between the different researchers. Overlap was identified and consistency was reached. Coinciding themes of importance were then put into a common framework. Data collection was terminated due to saturation when
Table 2 Summary of main themes

\begin{tabular}{|c|c|c|}
\hline Facilitators & Barriers & $\begin{array}{l}\text { Support from peers } \\
\text { and family }\end{array}$ \\
\hline $\begin{array}{l}\text { The } \\
\text { establishment } \\
\text { of an honest } \\
\text { and trustworthy } \\
\text { relationship } \\
\text { with the health } \\
\text { professional } \\
\text { Monitoring the } \\
\text { behavioural } \\
\text { change with } \\
\text { personal } \\
\text { feedback } \\
\text { Goal setting } \\
\text { Experiencing } \\
\text { significant life } \\
\text { events igniting } \\
\text { the right time for } \\
\text { action }\end{array}$ & $\begin{array}{l}\text { The perception of } \\
\text { insurmountable } \\
\text { obstacles } \\
\text { Experience of lack } \\
\text { of self-efficacy } \\
\text { Excess eating of } \\
\text { high-calorie food }\end{array}$ & $\begin{array}{l}\text { Experience of honest } \\
\text { and trustworthy } \\
\text { person-to-person } \\
\text { forums } \\
\text { Need for } \\
\text { acknowledgement } \\
\text { from referent others } \\
\text { Support from partner/ } \\
\text { spouse }\end{array}$ \\
\hline
\end{tabular}

no new themes emerged. The quotes that best illustrated the different themes and subthemes were selected and translated from Danish to English by CJB. All quotes were then evaluated by the remaining authors and changes were made to reach agreement among all authors.

\section{RESULTS}

All but one of the participants used smartphones or tablets. One only used a traditional cell phone and had his wife entering data via a computer. Five years after the initial intervention, they all still used the internet or apps for benefiting their health, even though they no longer had access to the intervention tool, www.slankedoktor.dk, described in accordance with (Template for Intervention Description and Replication (TIDieR)) checklist ${ }^{19}$ and the Coventry, Aberdeen and London-Refined taxonomy ${ }^{20}$ in online supplementary appendix 1 . Everyone looked up recipes, some had joined weight-loss Facebook groups, and some used an app-based service monitoring their physical activity. They were not aware of all the functionality that could support them for free using their smartphones, but the majority acknowledged that the provided collaborative e-health tool had helped them during the intervention period. Following the 2 years' intervention study 5 years ago, some had gained weight, but not to the level before the intervention. We identified three main themes: facilitators, barriers, and the support of family and peers (see table 2).

\section{Facilitators for lifestyle change}

A number of subthemes were identified to facilitate longterm lifestyle change, but over all establishing an honest relationship with a healthcare professional, who was trusted to monitor the patient and able to set realistic goals with the patient, was most important. 
The establishment of an honest and trustworthy relationship with the health professional

For all successful lifestyle changes that had lasted for more than 3 months, the patient could refer to a person whom they trusted and who supported them in their efforts to lose weight. They all had a good and trustworthy relationship with their GPs. Six found support from the dietician involved in the study (including online support), one found support from the GP nurse, one found support from an online coach, one from a spiritual leader and one had not been successful. The four (three men and one woman) who had not found support in the dietician in the intervention were the least successful in the pilot study. ${ }^{13}$

I think it was really nice to see CA (the dietician), also because she could see it was my head that controlled me a lot. (P2, female)

Some of the patients said that they did not trust the dietician who had been assigned to them nor did they trust the e-health tool, and they identified the lack of trust as the main reason for discontinuing the intervention or seeking other guidance.

I can't have a settled plan..., well, it is more when I told it to her then I said: "it does not work for me. I can't use it that way", and then I actually did not return... (P5, male)

I felt the trust I had showed had been misused in a way, not that I don't want to join a group and talk about a lot of things, what I have eaten etc..., but all of a sudden another dietician sent me messages and then I said: "now it stops, now it (the information) is off track, that I don't want it and feel I can't control it. (P9, male)

One of the participants established contact with another online lifestyle coach who helped him to achieve a significant weight loss without a single face-to-face meeting, which means that 7 out of 10 had used online support for their weight loss and 3 had found face-to-face support from alternative sources that worked better for them.

\section{Monitoring the behavioural change with personal feedback}

All patients found it positive that their health professional of choice showed interest in their self-measurements.

One who had to see, that I kept my weight. If not, I would have said I had done it (lost weight), without having done it... to satisfy others... and I can't cheat it (an objective activity monitoring fitness app: "Endomondo"). It is not possible for me to pretend I have gone for a walk when I haven't. (P1, female)

\section{Goal setting}

Individual goal setting was recognised as difficult. Several patients revealed that they had daily or weekly goals for activity, diet or weight. Daily goals seemed most effective due to the fact that action was needed within small, discrete windows of time.

Today... I just have to walk my 10.000 steps, and swim two times a week. And then I eat what I always have eaten, except I don't eat that stof (candy), because I'm not tired, so I don't need it. (P8, female)

Then I stopped eating candy, and I have neither bought nor had candy for three months and I have lost $7 \mathrm{~kg}$. (P3, female)

\section{Experienced life events perceived as significant, igniting the right time for action}

All patients revealed how a specific situation or life event had ignited their lifestyle change. Five revealed that a specific incident in their family changed their way of thinking with regard to their lifestyle. Three had experienced that their doctor or another health professional had made it clear to them that they had to do something. Two had received an effective treatment that had helped them with their weight control or tiredness to a degree that made it possible to act in a different way.

...It was a very specific episode that ignited it (the lifestyle change)... I came home one night very tired... My husband is on his way to bed, and then he says: "by the way the kids and I found a bag of candy in your handbag that we ate - I hope that is okay?" I then went completely mad and wanted a divorce..., but then during the night, I realized that I had a problem. I had three kids, and I wanted to break up my marriage due to a bag of candy... (P10, female)

\section{Barriers to lifestyle change}

The patients gave many reasons as to why they had difficulties maintaining the weight loss, both in their own perception of insurmountable obstacles, experience of lack of self-efficacy and in having difficulties with excess eating of high-calorie foods, which is explained in more details below.

\section{The perception of insurmountable obstacles}

Several patients described how they used illnesses or other deficits to explain their lack of ability to do something about their health.

I had this knot under my left foot removed in surgery two years ago. Three months ago, I had the same operation in the other foot. So I'm not able to do it (exercise), and I still can't use regular footwear. I still use sandals. (P1, female)

\section{Experience of lack of self-efficacy}

Several patients explained how they often felt tempted to indulge in high-calorie foods, and that their confidence in being able to avoid inappropriate behaviour was low. 
It is probably because I can eat a little candy again or buy a chocolate bar when I'm out shopping.... And I have problems saying no thanks. (P2, female)

\section{Excess eating of high-calorie foods}

Many of the patients had experiences with their weight going up and down. When they allowed themselves to eat even small amounts of sweets, their weight went up very quickly.

It happened very fast. I think it was in December ... I allowed myself to eat a cookie... by the end of January, I had gained $10 \mathrm{~kg}$. Just like an alcoholic can't drink half a bottle of wine, then I will never be able to eat $100 \mathrm{~g}$ of chocolate without having to really hold myself back. (P10, female)

\section{Support from peers and family}

As severely overweight people, it is obvious to everyone you meet, that you have challenges in relation to your lifestyle. The support from friends and close family was found important, and intrinsic factors that inhibit weight loss can be both potentiated or challenged, when the person come into contact with other individuals.

\section{The experience of honest and trustworthy person-to-person forums}

Most patients found support from friends they had met in their struggle to lose weight. Both relations established in traditional meetings and online forums were described as important.

"Then I have my friend, whom I met when I joined Weight Watchers. She has all these ideas as to how to combine different food ingredients... and my other friend has that as well, but she has now joined this online group low fat, high something... (P6, female)

Several of the patients used Facebook or apps, where they communicated with friends. Several of the patients described how they experienced that they were able to communicate more honestly with their online friends.

...I'm more in need of a closed group for people who have the same problems as I have or at least are in the same position as I am and I could do it (be honest) if it was online, but not if I had to look them in the eyes.

If it is someone I would never meet, then I could be honest, but as soon I know that it is someone I am going to meet, then I add to the story. (P2, female)

\section{Need for acknowledgement from referent others}

To sustain a lifestyle change, most of the patients said that the most important person was their partner/spouse or another person close to them who continued to regard the lifestyle change as important. For most of the patients, the dietician or another healthcare professional had been the most important person during the period of lifestyle change. After the study, a number of the patients returned to their old habits, and the lack of support was missed.

The worst thing was that nobody called me up and said: "Why is it you have not scheduled a new appointment?" (P2, female)

In the online setting, acknowledgement also made a difference to a majority of the patients.

I used it (the forum in the e-health tool) a lot.... The fact that I could be honest and put my cards on the table, because they all knew how it is to have the urge to drive to the next baker and empty the store on the way home. So it was actually very important to me that I had that forum. (P10, female)

....It is the same with Endomondo (an activity tracker app). I have friends there. And then I have to show I walk. Not to make them believe I'm not active. (P7, female)

\section{Support from partner/spouse}

All patients shared their goals and achievements with their close family. Most found their family supportive, but a minority also revealed that the partner/spouse took a judgemental position with regard to their lifestyle choices and some tried to support their partner/spouse through loving teasing.

...Before I lost weight my breathing was really bad ... and I couldn't sleep at night so I would fall asleep during the day... then I would be reviled by $\mathrm{N}$ (partner): 'Now you are sitting falling asleep again' I could sit in a chair and fall asleep. (P4, male)

\section{DISCUSSION}

We aimed to identify important drivers for long-term lifestyle change for patients using a hybrid collaborative e-health tool and found that establishing a trustworthy relationship with a healthcare professional doing lifestyle coaching was the most important factor for a long-term successful lifestyle change. This matches the social ecological point of view that establishing a good relationship with the patient is of paramount importance for coaching patients to make difficult decisions. ${ }^{921} 22$ To establish a trustworthy relationship with a healthcare professional can be difficult in a fully online e-health tool. The provided e-health tool in this study used a hybrid model, both in-person and online, that seemed to strengthen the relationship with a healthcare professional even though some patients found strong and consistent support by themselves outside the GP setting or in alternative settings. The main reasons for non-adherence were lack of trust in the dietician, and lack of trust in the e-health tool, which is in alignment with other studies examining reasons for non-compliance with e-health tools. ${ }^{23}$

Goal setting and monitoring the behavioural change are important to many patients, but it needs to be delivered 
empathically and only when relevant. Goal-directed action is the basis of the $\mathrm{SAT}^{10}$ and, by using e-health tools, this can be done in real time both more objectively (via accelerometers in smartphones, using apps such as Google Fit, Apple's built-in Health app or Endomondo) and subjectively through reporting it. Lifestyle changes were often ignited by a specific event. This event could be intrinsic, from a perceived significant life event for the individuals or their close family, or extrinsic, such as an eye-opening talk with a health professional or an effective treatment that helped the patient decide that weight loss or other lifestyle changes were important enough to make a change.

Barriers centred around perceived insurmountable obstacles, lack of self-efficacy and excess eating of high-calorie foods, very much related to the intrapersonal stream described in the TTI. ${ }^{11}$ To close the gap and reach their goals despite these barriers, patients described how the support they experienced both offline and online from referent others made a huge difference. This interpersonal aspect is the second stream in TTI and confirms that meeting others in the same situation is important.

The third stream in TTI is the sociocultural environment that changes to some extent when a person meets new people (including online) who also want to lose weight. That is, you can change your online referent others ('friends'), something that might be of importance in the future, especially for people from lower social economic classes, with little support from friends and family. ${ }^{12}$ Many of the same psychological support elements via change of reference others, are found in other successful lifestyle change groups such as Alcoholics Anonymous and/or Overeaters Anonymous. Lastly, close family play an important role to our participants. The participants all reported support from their family as important during their weight loss, which is in accordance with the SCT underlying the importance of the opinion of referent others. ${ }^{9}$

\section{Strengths and limitations of this study}

This is the first qualitative research study exploring drivers for successful long-term lifestyle change using a collaborative online e-health approach in general practice. The digital revolution makes it difficult to detect general principles for successful e-health tools before they are outdated; instead, this qualitative study explores themes of importance across various persuasive technologies and collaborative e-health platforms that could not be highlighted in a quantitative study. It is a potential weakness that we do not know if our sample was more technically savvy than the average population, which should be addressed in future studies. On the other hand new technologies become more accessible all the time, that is why we believe the principles outlined in this study apply to most patients.

This study mainly included patients with successful longterm lifestyle change, meaning reasons for lack of engagement and non-adherence might have been overseen.
The study did not look into perspectives of individuals in relation to their outcomes, with more individuals and methodological triangulation, this might have revealed the quantitative importance of the identified themes. The result of this study is probably generalisable and supports the notion that the implementation of collaborative e-health tools might have the potential to change patient lifestyles through low-cost support for healthy living. The preconception of the authors CJB and JS, who are GPs, might have compromised the objectivity of the data in interviews and analysis, even though it was taken into account in the analysis. Future research needs to examine the perspectives of GPs and healthcare professionals who assist patients using collaborative e-health tools, in order to better understand the perspectives of all stakeholders.

\section{CONCLUSION}

A strong relationship with a healthcare professional or another person with coaching ability is essential for longterm successful weight loss when using e-health tools. The collaborative e-health tool can be viewed as a supplement to the professional empathic relationship and support behavioural change through monitoring and empathic, relevant feedback. The opinions of family and peers matter. Long-term success with lifestyle change depends on the ability to establish strong positive support on a day-to-day basis, which can be supported by e-health tools. The patient needs to feel that the healthcare professional cares for her/him if she/he is going to be successful with a long-term lifestyle change. The present findings are probably generalisable to the use of collaborative e-health tools and have formed the basis of the later development of a collaborative e-health tool using focus group interviews in a 'thinking aloud' protocol where the patients interact with the app and healthcare professionals interact with the back-end control panel ${ }^{24}$ that is going to be used in a future study. ${ }^{25}$

Contributors CJB, JC, JBN and JS have all contributed substantially to the conception and the design of the work, and analysis and interpretation of data. CJB, JC, JBN and JS have all been involved in drafting and revising the article critically for important intellectual content. CJB, JC, JBN and JS have all approved the final version attached, will approve the final published version and agree to be accountable for all aspects of the work in ensuring that questions related to the accuracy or integrity of any part of the work are appropriately investigated and resolved.

Funding The study has been partly funded by The Region of Southern Denmark, KEU project 07/10.

Competing interests CJB owns stock in LIVA Healthcare ApS, the company that has developed parts of the technical platform used by the patients in the pilot study. Patient consent Obtained.

Ethics approval The Regional Committees on Health Research Ethics for Southern Denmark.

Provenance and peer review Not commissioned; externally peer reviewed. Data sharing statement All 10 interviews can be provided in Danish on request.

Open Access This is an Open Access article distributed in accordance with the Creative Commons Attribution Non Commercial (CC BY-NC 4.0) license, which permits others to distribute, remix, adapt, build upon this work non-commercially, and license their derivative works on different terms, provided the original work is 
properly cited and the use is non-commercial. See: http://creativecommons.org/ licenses/by-nc/4.0/

(C) Article author(s) (or their employer(s) unless otherwise stated in the text of the article) 2018. All rights reserved. No commercial use is permitted unless otherwise expressly granted.

\section{REFERENCES}

1. Hall KD, Kahan S. Maintenance of Lost Weight and Long-Term Management of Obesity. Med Clin North Am 2018;102:183-97.

2. Sriram U, Morgan EH, Graham ML, et al. Support and Sabotage: A Qualitative Study of Social Influences on Health Behaviors Among Rural Adults. J Rural Health 2018;34.

3. Lupton D. The digitally engaged patient: Self-monitoring and selfcare in the digital health era. Social Theory \& Health 2013;11:256-70.

4. Afshin A, Babalola D, Mclean M, et al. Information technology and lifestyle: a systematic evaluation of internet and mobile interventions for improving diet, physical activity, obesity, tobacco, and alcoho use. J Am Heart Assoc 2016;5:e003058.

5. Hartmann-Boyce J, Johns DJ, Jebb SA, et al. Effect of behavioural techniques and delivery mode on effectiveness of weight management: systematic review, meta-analysis and meta-regression. Obes Rev 2014;15:598-609.

6. Sherrington A, Newham JJ, Bell R, et al. Systematic review and meta-analysis of internet-delivered interventions providing personalized feedback for weight loss in overweight and obese adults. Obes Rev 2016;17:541-51.

7. Lyons EJ, Lewis ZH, Mayrsohn BG, et al. Behavior change techniques implemented in electronic lifestyle activity monitors: a systematic content analysis. J Med Internet Res 2014;16:e192.

8. Levine DM, Savarimuthu S, Squires A, et al. Technology-assisted weight loss interventions in primary care: a systematic review. $J$ Gen Intern Med 2015;30:107-17.

9. Bandura A. Health promotion by social cognitive means. Health Educ Behav 2004;31:143-64.

10. Ewart CK. Changing our unhealthy ways: emerging perspectives from social action theory. Emerging theories in health promotion practice and research 2009;2:359-89.

11. Flay B, Snyder F, Petraitis J, et al. Emerging theories in health promotion practice and research. San Francisco: Jossey-Bass, 2009.
12. Winzelberg AJ, Classen C, Alpers GW, et al. Evaluation of an internet support group for women with primary breast cancer. Cancer 2003;97:1164-73.

13. Brandt V, Brandt CJ, Glintborg D, et al. Sustained weight loss during 20 months using a personalized interactive internet based dietician advice program in a general practice setting. International Journal on Advances in Life Sciences 2011;3.

14. Haste A, Adamson AJ, McColl E, et al. Web-Based Weight Loss Intervention for Men With Type 2 Diabetes: Pilot Randomized Controlled Trial. JMIR Diabetes 2017;2:e14.

15. Yip C, Han NR, Sng BL. Legal and ethical issues in research. Indian J Anaesth 2016;60:684-8.

16. Kvale S, Brinkmann S. Interviews: learning the craft of qualitative research interviewing. 3rd ed. United States of America: SAGE, 2015.

17. Malterud K. Qualitative research: standards, challenges, and guidelines. The Lancet 2001:358:483-8.

18. Sandelowski M. Focus on research methods-whatever happened to qualitative description? Research in nursing and health 2000;23:334-40.

19. Hoffmann TC, Glasziou PP, Boutron I, et al. Better reporting of interventions: template for intervention description and replication (TIDieR) checklist and guide. BMJ 2014;348:g1687.

20. Michie S, Ashford S, Sniehotta FF, et al. A refined taxonomy of behaviour change techniques to help people change their physical activity and healthy eating behaviours: the CALO-RE taxonomy. Psychol Health 2011;26:1479-98.

21. Zoffmann V, Harder I, Kirkevold M. A person-centered communication and reflection model: sharing decision-making in chronic care. Qual Health Res 2008:18:670-85.

22. Moyers TB, Miller WR. Is low therapist empathy toxic? Psychol Addict Behav 2013;27:878-84.

23. Lie SS, Karlsen B, Oord ER, et al. Dropout From an eHealth Intervention for Adults With Type 2 Diabetes: A Qualitative Study. J Med Internet Res 2017;19:e187.

24. LIVA. The nordic personal coaching platform selected by NHS England for lasting lifestyle changes. $2017 \mathrm{http}: / /$ www.livahealthcare. com (accessed 10 Dec 2017).

25. Brandt CJ, Brandt V, Pedersen M, et al. Long-term effect of interactive online dietician weight loss advice in general practice (LIVA) protocol for a randomized controlled trial. Int J Family Med 2014;2014:1-6. 